\title{
Patient-Ventilator Asynchronies: Clinical Implications and Practical Solutions
}

\author{
Lucia Mirabella, Gilda Cinnella, Roberta Costa, Andrea Cortegiani, Livio Tullo, Michela Rauseo, \\ Giorgio Conti, and Cesare Gregoretti
}

\author{
Introduction \\ Respiratory Physiology and Mechanical Ventilation \\ Asynchronies \\ Respiratory Drive \\ Ventilatory Need \\ Neural Inspiratory Time \\ Types of Asynchronies \\ Triggering Delay \\ Ineffective Effort \\ Auto-Triggering \\ Double-Triggering \\ Reverse-Triggering \\ Flow Asynchrony \\ Cycling Asynchronies \\ Clinical Implications \\ Ventilator-Induced Diaphragmatic Dysfunction \\ Difficult Weaning \\ Patient Discomfort and Cognitive Dysfunction \\ Dyspnea \\ How to Monitor Asynchronies \\ Visual Analysis \\ Esophageal Pressure \\ $\mathbf{E A}_{\text {di }}$ \\ Diaphragmatic Ultrasound \\ Automatic Methods \\ Strategies to Improve Patient-Ventilator Interaction \\ Conventional Ventilator Support \\ Nonconventional Ventilator Support \\ Summary
}

Mechanical ventilation is a supportive treatment commonly applied in critically ill patients.
Whenever the patient is spontaneously breathing, the pressure applied to the respiratory system
depends on the sum of the pressure generated by the respiratory muscles and the pressure gen-
erated by the ventilator. Patient-ventilator interaction is of utmost importance in spontaneously
breathing patients, and thus the ventilator should be able to adapt to patient's changes in venti-
latory demand and respiratory mechanics. Nevertheless, a lack of coordination between patient
and ventilator due to a mismatch between neural and ventilator timing throughout the respira-
tory cycle may make weaning difficult and lead to prolonged mechanical ventilation. Therefore, 


\section{Patient-Ventilator AsynChronies}

appropriate monitoring of asynchronies is mandatory to improve the applied strategies and thus improve patient-ventilator interaction. We conducted a literature review regarding patient-ventilator interaction with a focus on the different kinds of inspiratory and expiratory asynchronies, their monitoring, clinical implications, possible prevention, and treatment. We believe that monitoring patient-ventilator interaction is mandatory in spontaneously breathing patients to understand, by using the available technologies, the type of asynchrony and consequently improve the adaptation of the ventilator to the patient's needs. Asynchronies are relatively frequent during mechanical ventilation in critically ill patients, and they are associated with poor outcomes. This review summarizes the different types of asynchronies and their mechanisms, consequences, and potential management. The development and understanding of monitoring tools are necessary to allow a better appraisal of this area, which may lead to better outcomes for patients. Key words: asynchrony; diaphragm; dyspnea; intensive care units; mechanical ventilation; work of breathing. [Respir Care 2020;65(11):1751-1766. (C) 2020 Daedalus Enterprises]

\section{Introduction}

In critically ill patients, the ideal strategy throughout the duration of mechanical ventilation would be to allow the patient to generate spontaneous breaths as soon as possible to avoid diaphragmatic dysfunction due to prolonged controlled mechanical ventilation. ${ }^{1}$ However, during spontaneous breathing, the goal is to maintain synchronous interaction between the patient and the ventilator to reduce the patient's inspiratory effort while adapting the ventilator settings according to the changes in the patient's ventilatory demand and breathing mechanics. ${ }^{2-4}$ Nevertheless, patientventilator interaction is seldom optimized, causing asynchronies that can be defined as a lack of coordination between patient and ventilator due to a mismatch between neural and ventilator timing throughout the respiratory cycle or the magnitude of support provided and demanded. ${ }^{1,3-6}$

\section{Respiratory Physiology and Mechanical Ventilation}

The effects of mechanical ventilation on gas exchange, respiratory muscle load, and dyspnea depends on the match between the ventilatory setting and patient's respiratory physiology. As described by Ranieri et al, ${ }^{1}$ the patient is

Drs Mirabella, Cinnella, Tullo, and Rauseo are affiliated with the Department of Medical and Surgical Science, University of Foggia, Foggia, Italy. Drs Costa and Conti are affiliated with the Department of Anesthesia and Intensive Care, Fondazione Policlinico A. Gemelli IRCCS, Rome, Italy. Drs Cortegiani and Gregoretti are affiliated with the Department of Surgical, Oncological and Oral Science, Section of Anesthesia, Analgesia, Intensive Care and Emergency, Policlinico Paolo Giaccone, University of Palermo, Palermo, Italy. Dr Gregoretti is affiliated with Istituto Fondazione G Giglio, Cefalù, Italy.

The authors have disclosed no conflicts of interest.

Correspondence: Lucia Mirabella MD PhD, Department of Medical and Surgical Science, University of Foggia, V. le L. Pinto 1, 71122 Foggia, Italy.E-mail: lucia.mirabella@unifg.it.

DOI: $10.4187 /$ respcare. 07284 able to interact with the ventilator based on 3 physiologic variables: ventilatory drive, ventilatory need, and neural inspiratory time. ${ }^{7-11}$

At the same time, these physiologic variables should match 3 phase variables that define the mechanical breath: (1) the synchronization system (ie, inspiratory trigger) that begins inspiration (ie, trigger variable); (2) the pressure or volume variable that controls the mechanical breath gas delivery (ie, control variable); (3) the cycling-off criteria (ie, cycling variable). The synchronization system defines when the ventilator detects any patient inspiratory effort and activates a mechanical breath. The pressure or volume variable defines the type of control, namely volume or pressure, used by the ventilator to deliver the output. The cycling-off criteria define when the ventilator ends its support of the inspiratory effort, enabling the patient to exhale. ${ }^{1,12-20}$

\section{Asynchronies}

Patient-ventilator asynchrony, as mentioned above, is a lack of coordination between the patient and the ventilator due to a mismatch between neural and ventilator timing throughout the respiratory cycle or the magnitude of support provided and the support demanded..$^{3-6}$ Several factors may cause asynchronies (Fig. 1). Asynchronies according to the patient respiratory mechanics are shown in Figure 2. Asynchronies occur whenever there is a mismatch between the physiologic variables and the technological variables characterizing the ventilator functioning: respiratory drive (ie, inspiratory trigger asynchrony), ventilatory need (ie, control variable gas delivery asynchrony), and neural inspiratory time (ie, ventilator cycling variable asynchrony). ${ }^{1}$

\section{Respiratory Drive}

Inspiratory trigger asynchrony can be defined as a lack of coordination between the ventilator inspiratory start criteria and the patient's respiratory centers output (eg, triggering delay, ineffective trigger, auto-triggering). Asynchrony in 


\section{Patient-Ventilator AsynChronies}

the inspiratory phase may be caused by problems with the inspiratory trigger occurring independent of its algorithm. ${ }^{21}$ Although modern ventilators integrate flow or pressure triggers, the inspiratory effort required to trigger a breath may be a significant part of the total inspiratory effort. ${ }^{12-20,22-24}$ Therefore, the "best" triggering setting should reduce duration and intensity of the respiratory muscles at its minimum level, before the mechanical breath starts, while avoiding auto-triggering. Although the definition of the "best" trigger is still controversial, it is widely recognize that a good response time should be $<100 \mathrm{~ms}^{1}$

In a study in which flow and pressure trigger were compared, Aslanian et $\mathrm{al}^{25}$ reported that during a flow trigger the time and the effort for triggering were $43 \%$ shorter and $62 \%$ lower compared to their percentage during a pressure

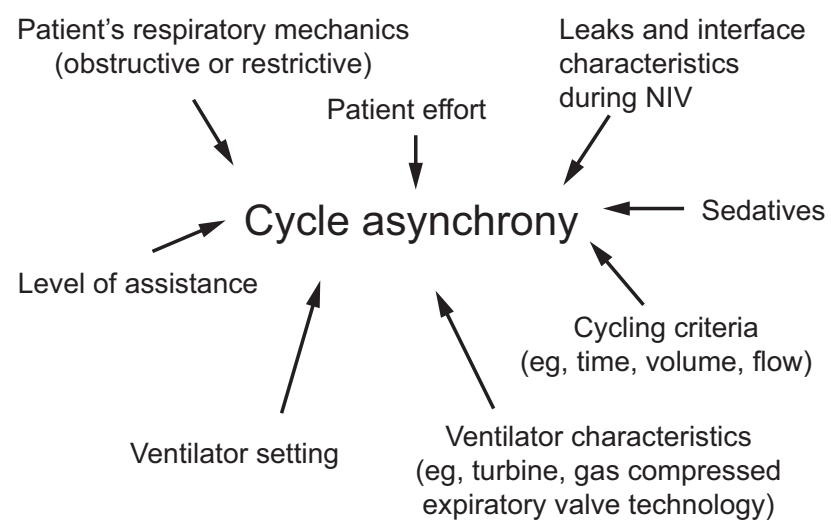

Fig. 1. Several factors may cause asynchrony, some related to patient characteristics (eg, respiratory mechanics, effort), others related to the ventilator (eg, setting, level of assistance, cycling criteria) and to the interface used (ie, invasive or noninvasive). NIV = noninvasive ventilation. trigger. However, the subjects' effort during the post-triggering phase were not significantly different during either trigger. A neural trigger, as a result of the introduction of a proper nasogastric tube, provided with an array of electrodes in the distal esophageal portion, can significantly improve patient-ventilator interaction. ${ }^{26-28}$

\section{Ventilatory Need}

Control variable gas delivery asynchrony can be defined as the ventilator not being able to meet the patient's ventilatory demand. ${ }^{1}$ Ward et $\mathrm{al}^{12}$ reported that increasing the flow during assisted volume control ventilation mode would result in a reduction of the patient's respiratory drive and work of breathing. Moreover, in volume control ventilation mode, any leak would decrease the ventilatory output. ${ }^{1,29}$ Conversely, a breath in pressure control ventilation mode better matches the patient's ventilatory needs because the flow is the dependent variable during the delivery of inspiratory pressure, which means it reproduces the physiologic descendent flow profile better. ${ }^{30}$

Nevertheless, the setting of pressure-rise time (ie, the time taken to reach the pressure set on the ventilator) may determine the flow output and consequently the asynchrony due to gas delivery. ${ }^{31,32}$ Although leaks are better compensated for in the pressure control ventilation mode than during the volume control ventilation mode, a severe leak, such as occurs during noninvasive ventilation (NIV), may decrease the ventilatory output in assisted pressure control ventilation mode. ${ }^{1,29,33-35}$

\section{Neural Inspiratory Time}

Ventilator cycling variable asynchrony can be defined as a mismatch between the patient's respiratory center's

\section{Asynchrony according to patient}

respiratory mechanics

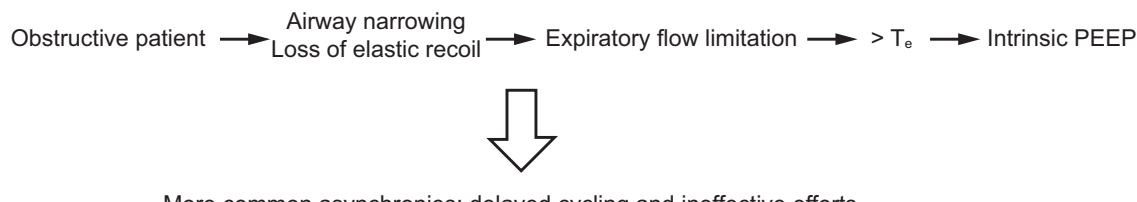

More common asynchronies: delayed cycling and ineffective efforts

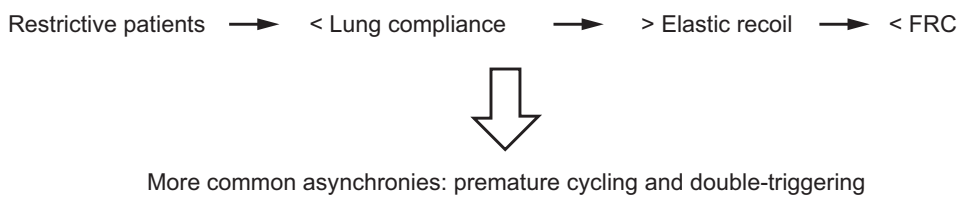

Fig. 2. Asynchronies are common in both obstructive and restrictive patients, although alterations of the underlying respiratory mechanics generate different types of asynchronies. $\mathrm{FRC}=$ functional residual capacity; $\mathrm{T}_{\mathrm{e}}=$ expiratory time constant. 


\section{Patient-Ventilator Asynchronies}

neurologic output and the ventilator's inspiratory time. ${ }^{36}$ Ventilator cycling asynchrony occurs when, after setting the cycling criteria (ie, pressure, time, volume, or flow), the mechanical breath is longer (ie, delayed cycling) or shorter (ie, premature cycling) than the patient's neural inspiration. ${ }^{1,25,32,37,38}$

\section{Types of Asynchronies}

Longhini et $\mathrm{al}^{39}$ classified asynchronies as major (ie, ineffective triggering, auto-triggering, double-triggering) or minor (ie, premature or short cycling, prolonged or delayed cycling, triggering delay). Table 1 lists different types of asynchronies and their definitions, causes, and strategies to resolve each asynchrony.

\section{Triggering Delay}

Triggering delay is a time lag between the onset of the patient's effort and the onset of ventilator pressurization. ${ }^{40}$ This is a typical asynchrony between the respiratory drive and the inspiratory trigger, where the phase lag quantifies the delay between the onset of the inspiratory muscle activity and the beginning of the mechanical breath. ${ }^{1,5,10,41}$

Giuliani et $\mathrm{al}^{42}$ reported that the effort performed by the patient during the triggering phase may interfere with the patient's effort during the remaining part of inspiratory phase. Interestingly, at higher inspiratory demand (ie, high respiratory drive), the trigger delay is shorter and the degree of the negative deflection in airway pressure $\left(\mathrm{P}_{\mathrm{aw}}\right)$ is greater.

Conversely, with a low inspiratory demand (ie, lower respiratory drive), trigger delay is longer and the negative deflection in $\mathrm{P}_{\mathrm{aw}}$ is smaller. ${ }^{7,40}$ Moreover, a threshold load, such as dynamic intrinsic PEEP, may worsen the triggering phase. $^{18}$

Finally, ventilator characteristics such as the position of the flow/pressure sensor (eg, inside the ventilator or proximally to the patient's airway) or a problem related to the valves, the interfaces chosen (endotracheal tube vs face mask or helmet), or the high resistances generated by a heat-and-moisture exchanger (HME) or by the endotracheal tube are all factors that may influence the trigger delay. ${ }^{17,20,22,43-47}$ To detect the triggering delay, the esophageal pressure or electrical activity of the diaphragm $\left(\mathrm{EA}_{\mathrm{di}}\right)$ is necessary. Figure 3 depicts a trigger delay of $>100 \mathrm{~ms}$.

\section{Ineffective Effort}

Ineffective effort is defined as a patient's effort being unable to trigger the ventilator breath. Ineffective effort is an asynchrony between respiratory drive and inspiratory trigger. From a clinical point of view, ineffective effort can be detected by analyzing the breathing frequency shown on the ventilator monitoring system that is lower than the breathing frequency monitored by observing the patient's chest/abdomen movements. ${ }^{1}$ Ineffective effort can also be identified by observing flow and $\mathrm{P}_{\mathrm{aw}}$ tracings on the ventilator monitor; a patient's effort that is unable to trigger the ventilator produces a $\mathrm{P}_{\mathrm{aw}}$ drop concomitant to a flow increase (Fig. 4). ${ }^{48}$

There are different causes leading to ineffective effort. A less sensitive inspiratory trigger in a patient with a low drive threshold may contribute to ineffective triggering. ${ }^{25}$ In patients with obstructive lung disease, an inspiratory threshold load, such as intrinsic PEEP as a consequence of air trapping, may cause ineffective triggering. ${ }^{49}$ An external PEEP in spontaneously breathing patients may counterbalance intrinsic PEEP and hence decrease inspiratory muscle effort. ${ }^{18,50}$

Younes et $\mathrm{al}^{51}$ reported that ineffective effort may also exacerbate dynamic hyperinflation. Metabolic alkalosis may cause ineffective effort in patients with chronic bicarbonate elevation and low carbon dioxide level due to depression of the neural respiratory drive. ${ }^{52}$ Sedative drugs may affect patients' respiratory drive and may decrease the ability of the respiratory muscles to trigger the ventilator; consequently, deep sedation is likely to produce an increased number of ineffective efforts. ${ }^{53}$ Several studies reported that a no-sedation protocol in subjects in the ICU was associated with a reduction of the asynchrony index, as well as a reduced duration of mechanical ventilation, in comparison to a daily interruption-of-sedation protocol. ${ }^{54,55}$ de Wit et $\mathrm{al}^{56}$ reported that the level of sedation relates to ineffective effort, with a significant increase of ineffective triggering index for every unit decrease on the Richmond Agitation-Sedation Scale. Vaschetto et $\mathrm{al}^{53}$ noted that, compared to light sedation, deep sedation with propofol reduces the respiratory drive and breathing pattern, significantly worsening patient-ventilator interaction.

Another cause of ineffective effort is asynchrony between the neural inspiratory time and the ventilator cycling variable. When the patient inspiratory time is shorter than the mechanical inspiratory time set on ventilator, the ventilator continues to insufflate the patient during neural expiration, thus causing hyperinflation. ${ }^{3}$ Leung et $\mathrm{al}^{7}$ observed that ineffective efforts were common during mandatory breaths in the intermittent mandatory ventilation mode because of the large tidal volume and the prolonged inspiratory time. For these reasons, the use of synchronized intermittent mandatory ventilation, especially in patients with COPD, is ineffective in unloading the respiratory muscles. ${ }^{7}$ Conversely, in a flow-cycled breath (eg, pressure support ventilation [PSV] mode), the duration of the mechanical inspiratory time is determined by the speediness of the pressure rise time and by the set flow threshold value (ie, the expiratory threshold, also called expiratory trigger). Ideally, the ventilator sensor should always track the end of 


\section{Patient-Ventilator Asynchronies}

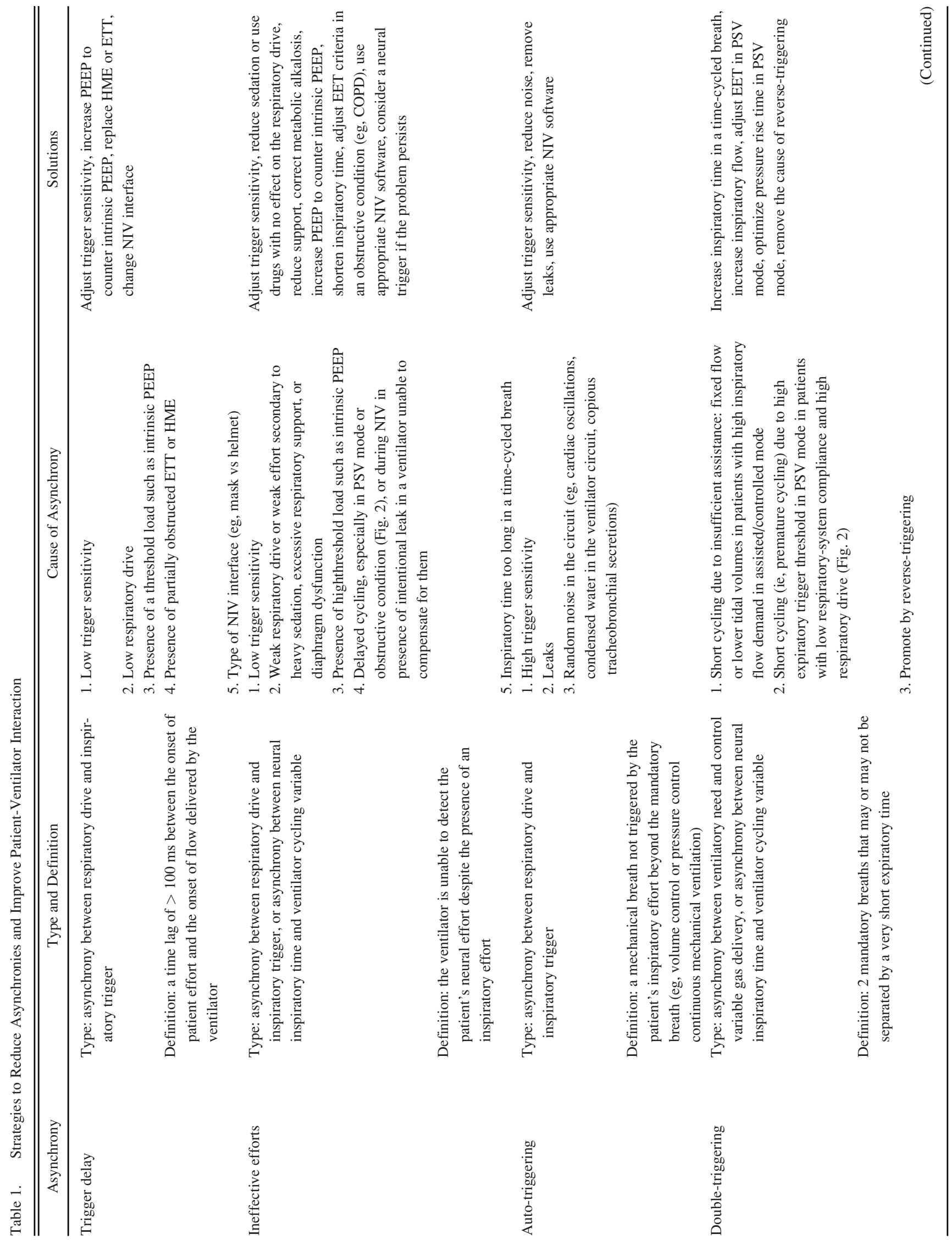




\section{Patient-Ventilator Asynchronies}

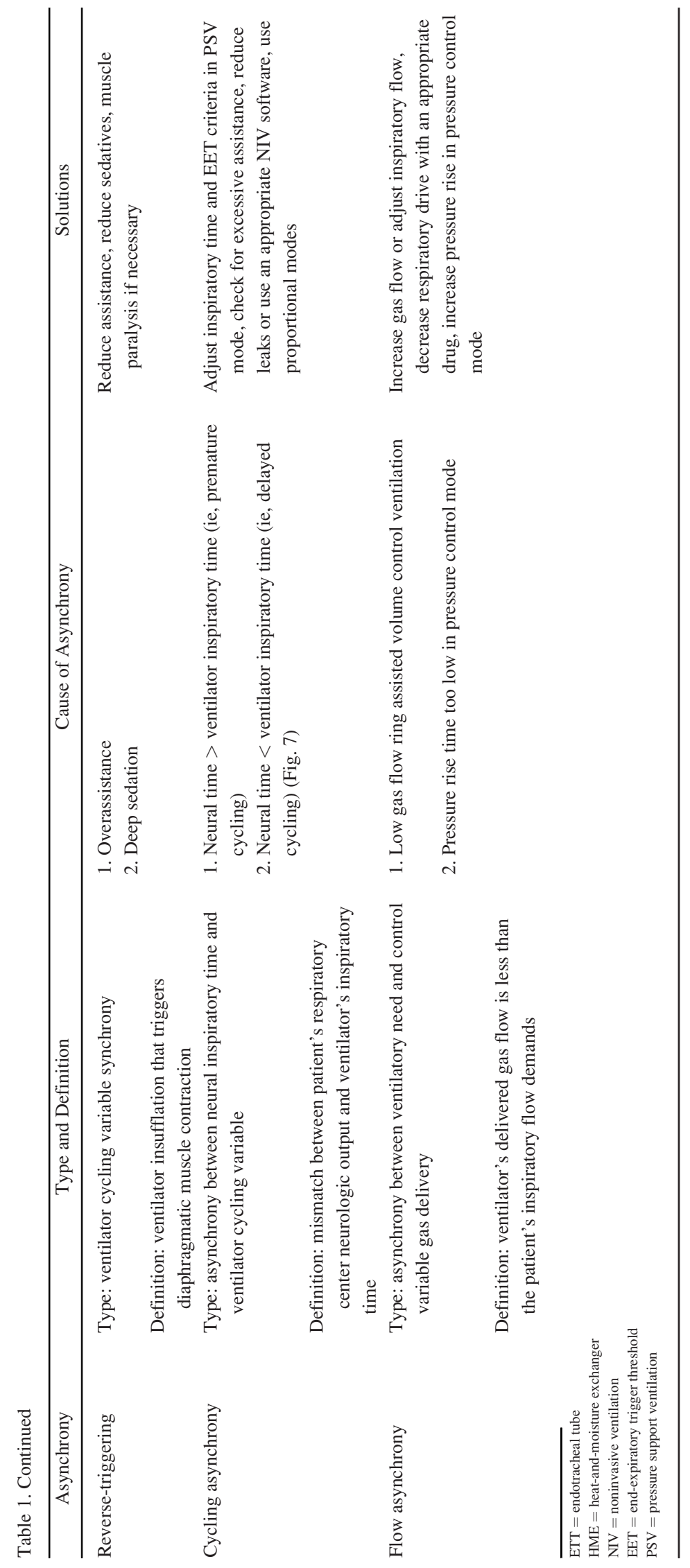



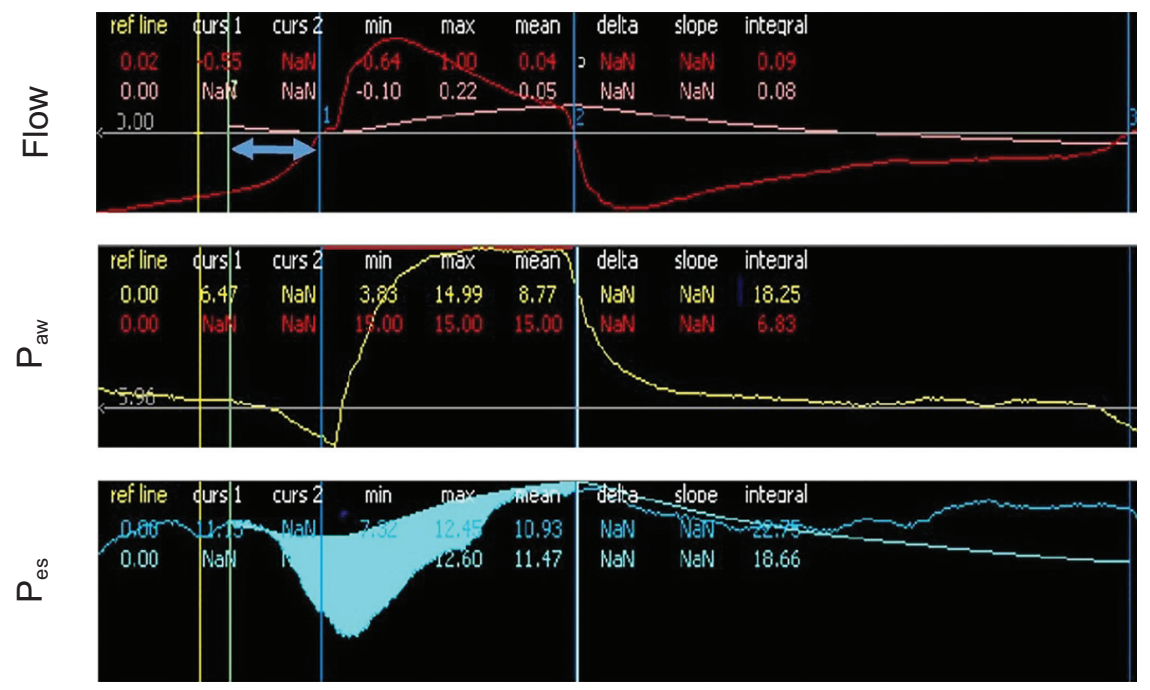

Fig. 3. Representative waveforms of flow (red track), $\mathrm{P}_{\mathrm{aw}}$ (yellow track), and $\mathrm{P}_{\mathrm{es}}$ (blue track) in a patient receiving ventilatory support. The blue arrow shows a delay of $>100 \mathrm{~ms}$ between the beginning of inspiratory muscle activity and the beginning of mechanical inflation (ie, trigger delay). $\mathrm{P}_{\mathrm{aw}}=$ airway pressure; $\mathrm{P}_{\mathrm{es}}=$ esophageal pressure.
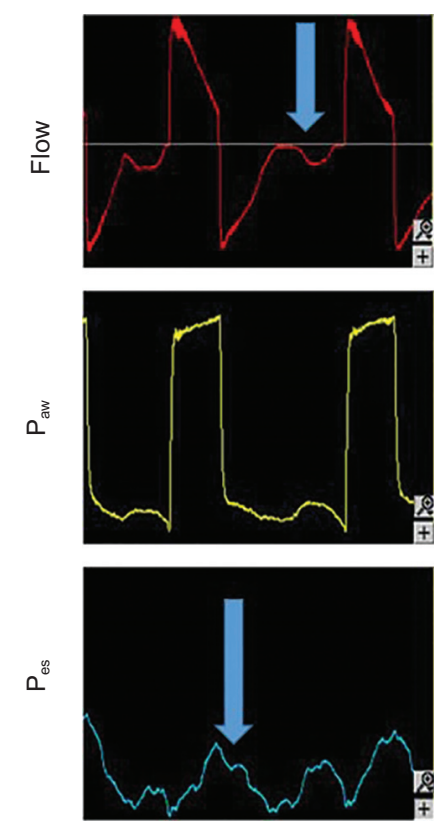

Fig. 4. Representative waveforms of flow (red track), $P_{a w}$ (yellow track), and $\mathrm{P}_{\mathrm{es}}$ (blue track) in a patient receiving ventilatory support. Arrows indicate ineffective effort. The ventilator is enable to detect the patient's effort as a deflection on $\mathrm{P}_{\text {es }}$ generating only a bump in Flow and $\mathrm{P}_{\mathrm{aw}}$ tracings. $\mathrm{P}_{\mathrm{aw}}=$ airway pressure; $\mathrm{P}_{\mathrm{es}}=$ esophageal pressure.

the patient's flow to assure synchrony. ${ }^{57,58}$ However, several factors may influence this relationship, such as patient respiratory mechanics, ventilator cycling algorithms, and ventilator settings. In patients with $\mathrm{COPD}$, the increased resistance and compliance produce a slower time-expiratory constant of the respiratory system. The longer time needed for the flow to fall to a low threshold value to trigger the expiration can lead to prolonged mechanical inspiration that persists during neural expiration. An appropriate cycling-off setting may reduce the incidence of ineffective effort. ${ }^{5,59,60}$ In addition, the presence of air leaks may impede a correct cycling in PSV, thus generating prolonged inspiratory time, especially when a dedicated NIV software is not used. ${ }^{61-63}$

Leung et $\mathrm{al}^{7}$ reported that a higher level of assistance might deeply decrease the patient's respiratory drive, prolonging the triggering time as defined by the onset of patient effort and the onset of flow delivery by the ventilator. This causes a prolongation of the ventilator breath into the patient's expiratory phase, thus decreasing the time available for the exhalation. ${ }^{44}$ In patients with COPD, this behavior will produce a larger tidal volume that is associated with a shorter expiratory time, which may determine dynamic hyperinflation and increase intrinsic PEEP. ${ }^{7,48,64}$

\section{Auto-Triggering}

Auto-triggering is a mechanical breath that is not triggered by the patient's inspiratory effort beyond the mandatory breaths (ie, in volume control or pressure control ventilation mode). ${ }^{1}$ It is an asynchrony between the respiratory drive and the inspiratory trigger. Auto-triggering can be caused by an extremely sensitive inspiratory trigger threshold or by changes in pressure and flow that may be related to random noise in the ventilator circuit (eg, condensate in the respiratory circuit, leaks, or cardiogenic 


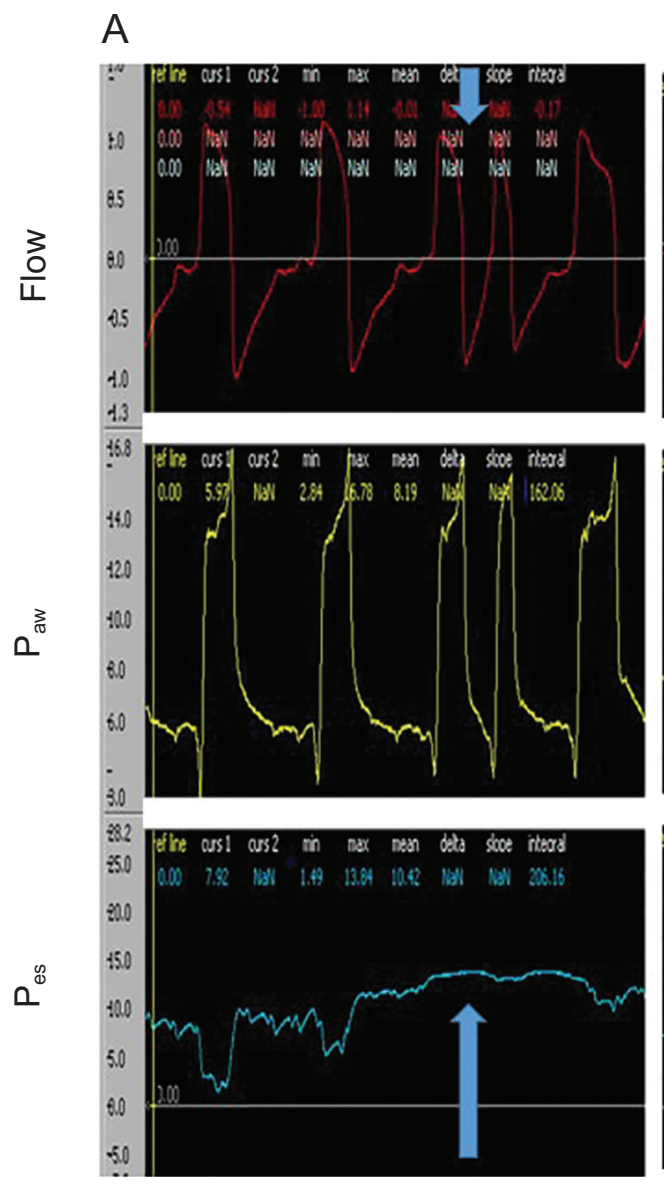

B
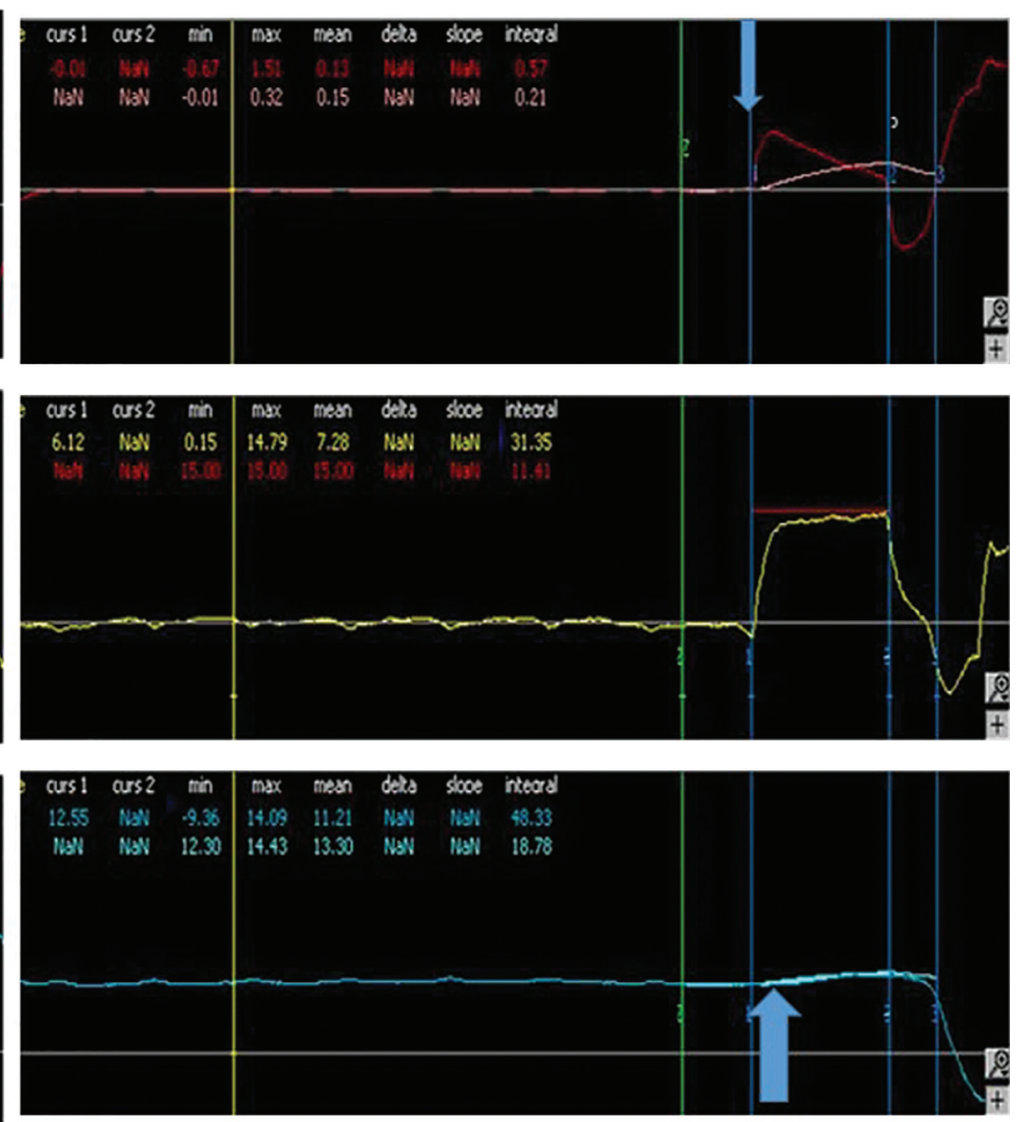

Fig. 5. Representative waveforms of flow (red track), $P_{\text {aw }}$ (yellow track), and $P_{\text {es }}$ (blue track) in a patient receiving ventilatory support showing 2 samples of auto-triggering (blue arrows). A: 3 mandatory breaths are delivered in the absence of the patient's inspiratory effort, separated by a very short expiratory time. B: A single mandatory breath is delivered in the absence of the patient's inspiratory effort. $P_{a w}=$ airway pressure; $\mathrm{P}_{\mathrm{es}}=$ esophageal pressure.

oscillations). ${ }^{46}$ In particular, a large stroke volume is able to trigger the breath by cardiac oscillation, especially when the sensitivity of the triggering is too high and the patient's drive is low (eg, a sedated patient). ${ }^{53,65}$ Potential consequences of auto-triggering are respiratory alkalosis, worsening intrinsic PEEP, and cardiac embarrassment. ${ }^{66}$ (Fig. 5).

\section{Double-Triggering}

Double-triggering, also called double-cycling or breathstacking, consists of 2 breaths that may or may not be separated by a very short expiratory time. Double-triggering is caused by high patient ventilatory demand coupled with a too-short ventilator inspiratory time compared to the patient's neural time; this causes 2 inspiratory cycles with a limited expiratory phase (Fig. 6). ${ }^{21,66,67}$

Double-triggering can be related to an asynchrony between neural inspiratory time and ventilator cycling variable or an asynchrony between ventilatory need and control variable gas delivery when the ventilator fails to meet the patient's flow demand. This results in the patient's neural effort continuing beyond the ventilator's inspiratory time. If the patient has a high respiratory drive, an additional breath can be generated with or without a very short expiratory time ${ }^{68,69}$ Double-triggering develops mainly when the ventilator delivers a fixed flow or when lower tidal volumes are set in the presence of high patient inspiratory flow demand. Double-triggering can also occur in the event of poor matching between neural and mechanical inspiratory times (ie, asynchrony between neural inspiratory time and ventilator cycling variable), especially when a high-flow termination criterion is applied to a restrictive lung condition in PSV mode. ${ }^{66}$

In the volume control ventilation mode, double-triggering may be particularly dangerous, especially in patients with ARDS under protective lung ventilation. ${ }^{70}$ Doubletriggering can generate high volumes and cause overinflation, thus inducing ventilator lung injury and a possible increase in right-ventricular afterload. ${ }^{66,69}$ Double- 


\section{Patient-Ventilator Asynchronies}
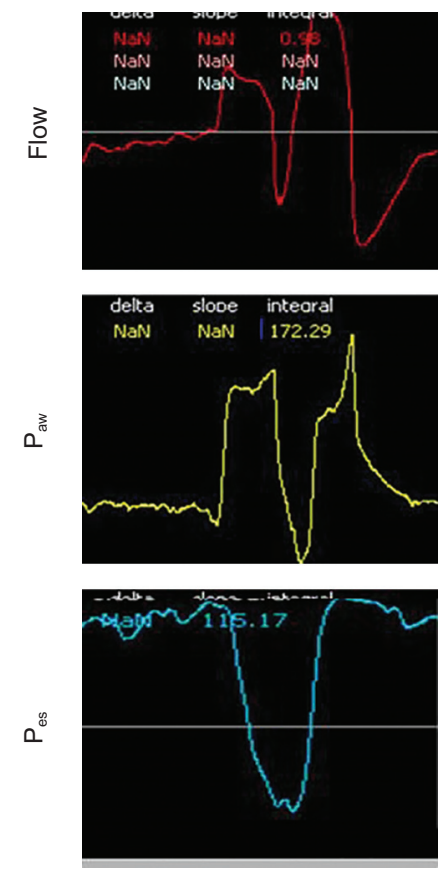

Fig. 6. Representative waveforms of flow (red track), $\mathrm{P}_{\mathrm{aw}}$ (yellow track), and $\mathrm{P}_{\mathrm{es}}$ (blue track) in a patient receiving ventilatory support. The figure shows a double-triggering in the pressure support ventilation mode depicted by the presence of 2 inspiratory cycles separated by a very short expiratory time. $\mathrm{P}_{\mathrm{aw}}=$ airway pressure; $\mathrm{P}_{\mathrm{es}}=$ esophageal pressure.

triggering in the pressure control ventilation mode seems to be less dangerous because alveolar pressure increases during inspiration with a concomitant decrease in the driving pressure of the next breath. ${ }^{71}$

\section{Reverse-Triggering}

Reverse-triggering is a type of asynchrony that happens when a patient's effort occurs after the initiation of a ventilator breath (ie, a breath not triggered by the patient). Usually, reverse-triggering represents an underrecognized asynchrony in which the ventilator triggers diaphragmatic muscle contractions through activation of the patient's respiratory center in response to passive insufflation of the lungs. ${ }^{72}$ With reverse-triggering, the effort frequently starts during the insufflation and continues during the expiration. The detection of patient effort that is triggered by a ventilator breath is easier to detect during pressure control ventilation because the flow changes when the effort occurs early enough in the inspiratory phase. Kallet et $\mathrm{al}^{73}$ reported this kind of asynchrony as a common observation during lungprotective ventilation. Because the patient's inspiratory muscles are still active at the beginning of expiration, preventing the elastic recoil of the respiratory system, the peak expiratory flow is markedly reduced. ${ }^{74}$ Reverse-triggering appears in deeply sedated patients, with or without lung injury, and it seems particularly common in those transitioning from sedated to awakened states. ${ }^{75}$ Interestingly, de Haro et $\mathrm{al}^{68}$ reported that one third of double-cycling breaths were reverse-triggered, primarily in association with deeply sedated subjects not triggering the ventilator.

\section{Flow Asynchrony}

Flow asynchrony is an asynchrony between ventilatory need and control variable gas delivery. Flow asynchrony occurs when the ventilator flow output does not coincide with the patient's demand. ${ }^{73,76}$ Inadequate gas delivery is common when ventilator flow is set inappropriately low, when the combination between tidal volume and inspiratory time does not result in adequate flow to the injured lung, or when inspiratory flow demands are high and vary from breath to breath. ${ }^{77}$ Flow asynchronies appear to be more common with ventilatory settings that deliver a fixed flow (ie, flow-targeted breaths) rather than with a flow that can vary with effort (ie, pressure-targeted breaths). ${ }^{78}$

\section{Cycling Asynchronies}

A cycling asynchrony can be defined as a mismatch between the patient's neurologic respiratory center and ventilator's inspiratory time. ${ }^{1,25,32,36-38}$ If the ventilator's set inspiratory time exceeds the patient's neurological inspiratory time, delayed cycling occurs. On monitor graphics, a pressure spike in PSV mode is detectable, originated by the recruitment of the expiratory muscles as a response to excessive muscle loading. ${ }^{72}$ Delayed cycling may occur because of nonintentional leaks that may prevent the ventilator from cycling from the inspiratory to the expiratory phase (ie, so-called inspiratory hang-up). This is more likely to be seen during NIV when the ventilators do not have software to compensate for air leaks or do not include a time criteria for cycling-off. ${ }^{61}$ Delayed cycling, especially in obstructive conditions (Fig. 2), may cause ineffective triggering. If the ventilator's set inspiratory time is less than the patient's neurological inspiratory time, short-cycling (ie, premature cycling) may occur. A high expiratory threshold time in PSV mode may also cause a short inspiration and lead to premature cycling, especially in patients with low compliance, such as in ARDS. ${ }^{72,79}$ If the patient's effort exceeds the time of mechanical support, another breath may also be generated (ie, double-triggering).

\section{Clinical Implications}

Asynchronies are often unrecognized, underestimated, and inappropriately treated. $5,24,27,80,81$ The asynchrony rate during invasive ventilation varies, widely ranging from $10 \%$ to $50 \%$, with a prevalence of ineffective efforts, especially in patients with COPD. ${ }^{48,80,82,83}$ 


\section{Patient-Ventilator AsynChronies}

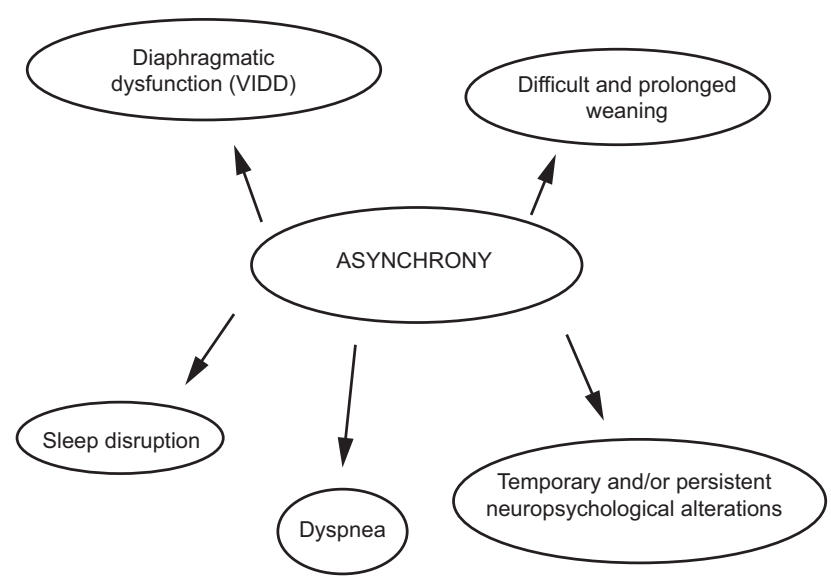

Fig. 7. Clinical implication of poor patient-ventilator interactions. VIDD $=$ ventilator-induced diaphragmatic dysfunction.

The incidence of asynchronies has been defined as the asynchrony index, which is a percentage value of the total number of asynchronous events divided by the sum of the total ventilator cycles plus the ineffective efforts. ${ }^{56,84} \mathrm{~A}$ high incidence of asynchrony is commonly defined as an asynchrony index $>10 \%$, and it may be related to a patient's discomfort, increased work of breathing, or prolonged weaning due mainly to wasted diaphragmatic energy. ${ }^{8,48,64}$ Several studies have reported that an asynchrony index $>10 \%$ may significantly increase the duration of mechanical ventilation and the risk of tracheostomy, and it may be associated with a higher mortality rate. ${ }^{3,56,85}$ Further studies are needed to define its role in predicting patient prognosis. A schematic representation of the clinical implications of poor patientventilator interactions is shown in Figure 7.

\section{Ventilator-Induced Diaphragmatic Dysfunction}

Ventilator-induced diaphragmatic dysfunction it is an important risk factor for poor patient-ventilator interaction, contributing to prolonged ventilator dependence and poorer outcome. ${ }^{86-91}$ During partial ventilator support, asynchronies can have an especially important impact on respiratory muscle function, in particular during ineffective efforts occurring in the exhalation phase of the previous mechanical breath, because the inspiratory muscles contract when they should relax as lung volume decreases to functional residual capacity. ${ }^{92}$ The result is a so-called eccentric or plyometric contraction, which leads to ultrastructural muscle damage, cytokine release, and muscle strength reduction with consequent deficit of force and weaning failure..$^{93-96}$

\section{Difficult Weaning}

Difficult weaning is closely related to asynchronies. Chao et $\mathrm{al}^{84}$ reported that the wasted diaphragmatic energy due to ineffective efforts had negative effects on the weaning process, significantly prolonging mechanical ventilation in subjects with an asynchrony index $>10 \%$ compared to those with an asynchrony index $<10 \%$. More recently, de Wit et $\mathrm{a}^{56}$ demonstrated that asynchrony index $>10 \%$ was related to longer duration of mechanical ventilation and shorter ventilator-free survival, along with lower likelihood of home discharge. A similar trend toward longer mechanical ventilation was confirmed by other studies that also noted an association between an asynchrony index > $10 \%$ and a higher mortality rate..$^{48,85}$

\section{Patient Discomfort and Cognitive Dysfunction}

Sleep quality may be deeply influenced by patient-ventilator interaction, and a high percentage of asynchronies appear to be responsible for sleep disruption. ${ }^{97}$ An improvement of sleep quality may be obtained with the reduction of the ventilatory support, which leads to a more stable breathing pattern, fewer missed efforts, and periodic breathing. ${ }^{92,98}$ Furthermore, the type of ventilatory support may play a role in sleep quality by reducing the number of asynchronies. ${ }^{66,97,98}$ However, the relationship between the patient-ventilator interaction and quality of sleep is still controversial. Alexopoulou et $\mathrm{al}^{99} \mathrm{did}$ not observe improvements in sleep quality during proportional assist ventilation+ compared to PSV, despite the former being able to improve patient-ventilator interaction, whereas neurally adjusted ventilatory assist was found able to improve sleep quality compared to PSV. ${ }^{100}$

\section{Dyspnea}

Dyspnea, defined as breath discomfort, is a common consequence of poor interaction between the patient and the ventilator and is strongly associated with anxiety in mechanically ventilated patients. ${ }^{101}$ In up to one third of patients, changes in ventilatory settings are able to reduce dyspnea and the associated anxiety, whereas the inability to reduce dyspnea by modifying ventilator settings seems to be associated with delayed extubation. ${ }^{66}$ The relationship between dyspnea and asynchronies still needs to be thoroughly investigated. ${ }^{81}$ Finally, asynchronies are associated with persistent neuropsychological alterations in critically ill patients. ${ }^{102}$ A profound sleep disruption with a high frequency of arousals and awakenings is related with acute onset of impaired cognitive function, visual hallucinations, delusions, and illusions. ${ }^{103,104}$

\section{How to Monitor Asynchronies}

The importance of an accurate analysis and quantification of asynchronies is mandatory. 3,66 However, precise analysis is still challenging in everyday clinical practice. ${ }^{105}$ 


\section{Patient-Ventilator Asynchronies}

\section{Visual Analysis}

Different patterns of asynchrony can be detected by visual inspection of flow/time and pressure/time waveforms in ventilated patients. Ineffective effort and double-triggering are the most common and easily detected asynchronies. ${ }^{92}$ Although a bedside evaluation of respiratory waveforms is a traditionally accepted and reliable method to identify asynchronies, ${ }^{106-108}$ this technique requires specific skills and expertise. ${ }^{109-111}$ It has also been suggested that an incorrect estimation of the patient's breathing frequency is one of the consequences of the difficulties in appreciating patient-ventilator asynchronies ${ }^{56,81}$ Furthermore, while the identification of asynchronies appears easy in extreme situations in which the patient "fights the ventilator," in other circumstances it is more difficult to detect asynchronies because most of them occur without any clinical signs. ${ }^{48,56}$

Therefore, specific training appears to be crucial for correct asynchrony detection. Colombo et $\mathrm{al}^{110}$ studied the accuracy of experienced ICU physicians in detecting asynchronies in comparison with less experienced physicians (ie, first-year residents); both groups had poor performance because of the absence of specific training. These results are in line with the data reported by Chacòn et al. ${ }^{111}$ In addition, the use of additional signals that reflect the patient's respiratory efforts is often required to increase the ability to recognize the asynchronies. ${ }^{112}$

\section{Esophageal Pressure}

The use of esophageal pressure allows the clinician to detect every inspiratory effort, thus providing accurate information regarding the patient-ventilator interaction. ${ }^{13}$ The simultaneous observation of $\mathrm{P}_{\mathrm{aw}}$, inspiratory flow, expiratory flow, and esophageal pressure waveforms allows the clinician to correctly match the patient's inspiratory effort with each mechanical breath. This may enable the identification of ineffective effort as an esophageal pressure deflection that is not followed by a ventilator cycle. ${ }^{105}$ However, even if this is the standard technique for asynchrony detection, this measurement is still not available yet for routine use in daily practice due to its invasiveness. ${ }^{114,115}$

$\mathbf{E A}_{\text {di }}$

A specific nasogastric tube provided with a multiple array of electrodes allows the continuous recording of the $\mathrm{EA}_{\mathrm{di}}{ }^{27,37,116}$ Only one ventilator uses this signal for triggering. $\mathrm{EA}_{\mathrm{di}}$ enables the detection of the onset and duration of the neural breath. ${ }^{105}$ However, like the esophageal pressure measurement, $\mathrm{EA}_{\mathrm{di}}$ does not represent a routine measurement in clinical practice. ${ }^{66}$

\section{Diaphragmatic Ultrasound}

Another method to detect asynchronies is the diaphragmatic ultrasound. The direct observation of the diaphragm thickening can allow the detection of the patient's inspiratory effort. ${ }^{117}$ This simple and noninvasive approach is still not standardized, and it requires the synchronization of ventilator waveforms with the diaphragmatic ultrasound signal, so its use still requires investigation. ${ }^{118}$

\section{Automatic Methods}

The real-time automatic detection of asynchronies, based on a machine learning approach, is a promising method aimed at identifying and quantifying asynchronies breath by breath without being affected by any kind of noise, such as secretions and body movements. ${ }^{105,115}$ Most systems today are intended to identify the most common asynchronies, such as ineffective efforts. Chen et $\mathrm{al}^{119}$ evaluated software dedicated to the detection of ineffective efforts, using a computerized algorithm based on the characteristic features of flow and $\mathrm{P}_{\mathrm{aw}}$ deflections. The investigators applied their software to 14 mechanically ventilated adult subjects demonstrating a sensitivity and specificity $>90 \%$ in detecting ineffective triggering. ${ }^{119}$ Mulqueeny et al ${ }^{120}$ studied an algorithm embedded in a ventilator system that was able to automatically detect the occurrence of ineffective effort and double-triggering in real time. The software was applied during both invasive and noninvasive ventilation, and it showed an overall accuracy of $>95 \%$. $^{120}$ Younes et al ${ }^{121}$ developed a new approach for monitoring and improving patient-ventilator interaction that uses a signal generated by the equation of motion. More recently, Blanch et $\mathrm{al}^{122}$ validated a software that is able to detect ineffective effort during invasive ventilation, as well as other kinds of asynchronies such as double-triggering, aborted inspiration, and short and prolonged cycling. Other systems aimed at automatically and noninvasively detecting asynchronies have been developed, such as spectral analysis of airway flow, the comparison between $\mathrm{P}_{\mathrm{aw}}$ and $\mathrm{EA}_{\mathrm{di}}$ waveforms, and specific algorithms. ${ }^{83,123}$

\section{Strategies to Improve Patient-Ventilator Interaction}

\section{Conventional Ventilator Support}

Patient-ventilator interaction is strongly influenced by the ventilatory mode and settings used, as well as by the type and level of sedation. In conventional ventilation, trigger settings may affect patient-ventilator interaction. In fact, a low sensitivity setting for the inspiratory trigger may increase triggering effort, while an oversensitive trigger may cause auto-triggering, especially in cases of decreased 


\section{Patient-Ventilator Asynchronies}

neuromuscular drive like polyneuromyoathy. ${ }^{65,89,106}$ During invasive ventilation, auto-triggering may be caused by noise in the ventilator circuit (eg, condensate in the respiratory circuit), whereas during NIV auto-triggering is caused mainly by nonintentional leak. ${ }^{46,63}$ It is worth noting that, among the new algorithms recently developed to improve patient-ventilator interaction, the neural trigger seems to be able to improve all of the drawbacks of triggering asynchronies, including those due to the presence of inspiratory PEEP and leaks. ${ }^{26-28}$

High levels of support have several detrimental effects on the ventilated patient, most notably hyperventilation, which may cause ineffective efforts, sleep fragmentation, and eventually apnea. ${ }^{98}$ High levels of support should be avoided in patients affected by chronic heart failure, who are particularly exposed to central apnea and abnormal breathing pattern, due to increased chemoreceptor sensitivity. In patients with COPD, a high level of support, especially when associated with a low expiratory threshold, prolongs the mechanical insufflations after the end of the neural inspiratory time, causing dynamic hyperinflation and consequent ineffective efforts. ${ }^{48,124}$ Chao et $\mathrm{al}^{84}$ reported that reducing the level of pressure support in subjects with COPD was the most effective strategy to decrease the number of ineffective efforts.

As previously explained, the patient-ventilation interactions worsen because of inappropriate inspiratory flow in continuous mandatory ventilation or an inadequate pressure rise time influencing the duration of a PSV breath. ${ }^{12,31}$ Finally, air leaks may affect both pressure control and volume control ventilatory support, but to a greater extent for the latter. ${ }^{1}$

Properly setting the inspiratory time is another important aspect of conventional ventilation. Mechanical breaths that are too long or too short may cause asynchronies due to poor matching between the neural and mechanical inspiratory times. 3,21,67,92 This could happen during time-cycled modes (eg, volume control or pressure control ventilation) or during a flow-cycled breath (ie, PSV mode) when the expiratory flow threshold is improperly set. ${ }^{58,66}$ Nonintentional leaks during NIV with ventilators that do not have leak-compensation software may increase the time of mechanical breaths, thus worsening patient-ventilator interaction. ${ }^{61,63,125}$ The application of appropriate external PEEP in patients with COPD may help reduce ineffective efforts. ${ }^{126,127}$

Sedation has as an important effect on patient-ventilator interaction. It is well known that deep sedation may increase the number of missed efforts. ${ }^{128}$ Nonsedated patients often show higher breathing frequency, with a relevant frequency of double-triggering. ${ }^{54}$ Vaschetto et $\mathrm{al}^{53}$ reported that deep sedation with propofol significantly reduce the respiratory drive as assessed with $\mathrm{EA}_{\mathrm{di}}$, whereas lower doses of propofol had fewer or no effects on patientventilator interaction. ${ }^{7}$ Interestingly, dexmedetomidine compared with propofol resulted in fewer asynchronies without influencing respiratory timing or drive. ${ }^{129}$ Costa et $\mathrm{al}^{130}$ reported no effect of incremental doses of remifentanil, a potent short-acting opioid drug, on respiratory drive, although there was an increase in the neural expiratory time, which resulted in a parallel reduction of breathing frequency.

\section{Nonconventional Ventilator Support}

Proportional assist ventilation and neurally-adjusted ventilatory assist are new modes of ventilation that provide assistance that is proportional to the patient's inspiratory effort; these modes can reduce asynchronies, as demonstrated by an increasing amount of data. ${ }^{4,131-134}$ In comparison with PSV, both proportional assist ventilation and neurally-adjusted ventilatory assist are able to prevent hyperinflation, improve neuro-mechanical coupling, restore the variability of the patient's respiratory pattern, and improve patient-ventilator interaction. ${ }^{135,136}$ It has been suggested that these innovative modes of ventilation should be considered when asynchronies persist after conventional ventilation adjustments. ${ }^{81}$

Noisy ventilation, a variable mechanical ventilation mode that is introduced by a variability in the respiratory pattern, is supposed to be beneficial to the respiratory function and to be less harmful to the sick lung than traditional PSV. ${ }^{137}$ Noisy or variable PSV applies a random variation in support levels, thus improving lung function and reducing pulmonary inflammatory response. ${ }^{138}$ Spieth et al ${ }^{139}$ reported that during noisy PSV, with randomly generated pressure support values according to a Gaussian distribution, the number of asynchronies was lower in comparison with conventional PSV. Furthermore, noisy PSV does not require closed-loop mechanisms or the insertion of an esophageal catheter, which make it technically easier to implement.

\section{Summary}

The monitoring of patient-ventilator interaction is a crucial aspect in treating spontaneously breathing patients and should be mandatory. Understanding the correct genesis of the various types of asynchronies, independent of available technologies, would improve patient-ventilation interaction and could eventually improve patient outcomes.

\section{REFERENCES}

1. Ranieri VM, Squadrone V, Appendini L, Gregoretti C. Patient-ventilator interaction. In: Vincent J-L, Abraham E, Moore FA, Kochanek PM, Fink MP, editors. Textbook of critical care, 7 th ed. Philadelphia: Elsevier; 2017:366-372. 


\section{Patient-Ventilator AsynChronies}

2. Brochard L, Harf A, Lorino H, Lemaire F. Inspiratory pressure support prevents diaphragmatic fatigue during weaning from mechanical ventilation. Am Rev Respir Dis 1989;139(2):513-521.

3. Sassoon CS, Foster GT. Patient-ventilator asynchrony. Curr Opin Crit Care 2001;7(1):28-33.

4. Kacmarek RM, Pirrone M, Berra L. Assisted mechanical ventilation: the future is now! BMC Anesthesiol 2015;15:110

5. Tobin MJ1, Jubran A, Laghi F. Patient-ventilator interaction. Am J Respir Crit Care Med 2001;163(5):1059-1063.

6. Garofalo E, Bruni A, Pelaia C, Liparota L, Lombardo N, Longhini F, Navalesi P. Recognizing, quantifying and managing patient-ventilator asynchrony in invasive and noninvasive ventilation. Expert Rev Respir Med 2018;12(7):557-567.

7. Leung P, Jubran A, Tobin MJ. Comparison of assisted ventilator modes on triggering, patient effort, and dyspnea. Am J Respir Crit Care Med 1997;155(6):1940-1948.

8. Dick CR1, Sassoon CS. Patient-ventilator interactions. Clin Chest Med 1996;17(3):423-438.

9. Mead J. Control of respiratory frequency. J Appl Physiol 1960;15 (3):325-336.

10. Hubmayr RD, Abel MD, Rehder K. Physiologic approach to mechanical ventilation. Crit Care Med 1990;18(1):103-113.

11. Whitelaw WA, Derenne JP, Milic-Emili J. Occlusion pressure as a measure of respiratory center output in conscious man. Respir Physiol 1975;23(2): 181-199.

12. Ward ME, Corbeil C, Gibbons W, Newman S, Macklem PT. Optimization of respiratory muscle relaxation during mechanical ventilation. Anesthesiology 1988;69(1):29-35.

13. Puddy A, Younes M. Effect of inspiratory flow rate on respiratory output in normal subjects. Am Rev Respir Dis 1992;146(3):787-789.

14. Georgopoulos D, Mitrouska I, Bshouty Z, Anthonisen NR, Younes M. Effects of non-REM sleep on the response of respiratory output to varying inspiratory flow. Am J Respir Crit Care Med 1996;153 (5): 1624-1630.

15. Laghi F, Karamchandani K, Tobin MJ. Influence of ventilator settings in determining respiratory frequency during mechanical ventilation. Am J Respir Crit Care Med 1999;160(5):1766-1770.

16. Banner MJ1, Blanch PB, Gabrielli A. Tracheal pressure control provides automatic and variable inspiratory pressure assist to decrease the imposed resistive work of breathing. Crit Care Med 2002;30 (5):1106-1111.

17. MacIntyre NR. Improving patient/ventilator interactions. In, Vincent $\mathrm{J}-\mathrm{L}$, editor. Yearbook of intensive care and emergency medicine. Berlin: Springer-Verlag; 1999:235-243.

18. Ranieri VM, Mascia L, Petruzzelli V, Bruno F, Brienza A, Giuliani $R$. Inspiratory effort and measurement of dynamic intrinsic PEEP in COPD patients: effects of ventilator triggering systems. Intensive Care Med 1995;21(11):896-903.

19. Alberti A, Gallo F, Fongaro A, Valenti S, Rossi A. P0.1 is a useful parameter in setting the level of pressure support ventilation. Intensive Care Med 1995;21(7):547-553.

20. Sassoon CS, Gruer SE. Characteristics of the ventilator pressure- and flow-trigger variables. Intensive Care Med 1995;21(2):159-168.

21. Hill LL, Pearl RG. Flow triggering, pressure triggering, and autotriggering during mechanical ventilation. Crit Care Med 2000;28(2):579581.

22. Fabry B, Haberthür C, Zappe D, Guttmann J, Kuhlen R, Stocker R. Breathing pattern and additional work of breathing in spontaneously breathing patients with different ventilatory demands during inspiratory pressure support and automatic tube compensation. Intensive Care Med 1997;23(5):545-552.

23. Ranieri VM, Giuliani R, Mascia L, Grasso S, Petruzzelli V, Puntillo $\mathrm{N}$, et al. Patient-ventilator interaction during acute hypercapnia: pressure-support vs. proportional-assist ventilation. J Appl Physiol (1985) 1996;81(1):426-436.

24. Nava S, Bruschi C, Fracchia C, Braschi A, Rubini F. Patient-ventilator interaction and inspiratory effort during pressure support ventilation in patients with different pathologies. Eur Respir J 1997;10 (1):177-183.

25. Aslanian P, El Atrous S, Isabey D, Valente E, Corsi D, Harf A, et al. Effects of flow triggering on breathing effort during partial ventilatory support. Am J Respir Crit Care Med 1998;157(1):135-143.

26. Sinderby C, Navalesi P, Beck J, Skrobik Y, Comtois N, Friberg S, et al. Neural control of mechanical ventilation in respiratory failure. Nat Med 1999;5(12):1433-1436.

27. Beck J, Gottfried S B, Navalesi P, Skrobik Y, Comtois N, Rossini M, Sinderby C. Electrical activity of the diaphragm during pressure support ventilation in acute respiratory failure. Am J Respir Crit Care Med 2001;164(3):419-424.

28. Navalesi P, Costa R. New modes of mechanical ventilation: proportional assist ventilation, neurally adjusted ventilatory assist, and fractal ventilation. Curr Opin Crit Care 2003;9(1):51-58

29. Beck J, Sinderby C, Lindström L, Grassino A. Effects of lung volume on diaphragm EMG signal strength during voluntary contractions. J Appl Physiol (1985) 1998;85(3):1123-1134

30. Boysen PG, McGough E. Pressure-control and pressure support ventilation: flow patterns, inspiratory time, and gas distribution. Respir Care 1988;33:126-134.

31. Kacmarek RM, Chipman D. Basic principles of ventilator machinery. In: Tobin MJ, editor. Principles and practice of mechanical ventilation, 2nd ed. New York: McGraw-Hill; 2006:53-95.

32. Chatburn RL. Classification of mechanical ventilators. In: Tobin MJ, editor. Principles and practice of mechanical ventilation, 2nd ed. New York: McGraw-Hill; 2006:37-52.

33. Smith IE, Shneerson JM. A laboratory comparison of four positive pressure ventilators used in the home. Eur Respir J 1996;9(11):24102415.

34. Carlucci A, Schreiber A, Mattei A, Malovini A, Bellinati J, Ceriana $\mathrm{P}$, Gregoretti $\mathrm{C}$. The configuration of bi-level ventilator circuits may affect compensation for non-intentional leaks during volume-targeted ventilation. Intensive Care Med 2013;39(1):59-65.

35. Gregoretti C, Pisani L, Cortegiani A, Ranieri VM. Noninvasive ventilation in critically ill patients. Crit Care Clin 2015;31(3):435-457.

36. Kacmarek RM, Villar J, Blanch L. Cycle asynchrony: always a concern during pressure ventilation! Minerva Anestesiol 2016;82 (7):728-730.

37. Parthasarathy S, Jubran A, Tobin MJ. Cycling of inspiratory and expiratory muscle groups with the ventilator in airflow limitation. Am J Respir Crit Care Med 1998;158(5 Pt 1):1471-1478.

38. Tobin MJ, Yang KL, Jubran A, Lodato RF. Interrelationship of breath components in neighboring breaths of normal eupneic subjects. Am J Respir Crit Care Med 1995;152(6):1967-1976.

39. Longhini F, Colombo D, Pisani L, Idone F, Chun P, Doorduin J, et al. Efficacy of ventilator waveform observation for detection of patientventilator asynchrony during NIV: a multicentre study. ERJ Open Res 2017;3(4):00075-2017.

40. Olivieri C, Costa R, Conti G, Navalesi P. Bench studies evaluating devices for non-invasive ventilation: critical analysis and future perspectives. Intensive Care Med 2012;38(1):160-167.

41. Iotti G, Braschi A, Locatelli A, Bellinzona G. Spontaneous respiration in artificial ventilation. Importance of valve resistance. Presse Med 1985;14(3):165-166.

42. Giuliani R, Mascia L, Recchia F, Caracciolo A, Fiore T, Ranieri VM. Patient-ventilator interaction during synchronized intermittent mandatory ventilation. Effects of flow triggering. Am J Respir Crit Care Med 1995;151(1):1-9. 


\section{Patient-Ventilator AsynChronies}

43. Racca F, Appendini L, Gregoretti C, Stra E, Patessio A, Donner CF, Ranieri VM. Effectiveness of mask and helmet interfaces to deliver noninvasive ventilation in a human model of resistive breathing. J Appl Physiol 2005;99(4):1262-1271.

44. Costa R, Navalesi P, Antonelli M, Cavaliere F, Craba A, Proietti R, Conti G. Physiologic evaluation of different levels of assistance during noninvasive ventilation delivered through a helmet. Chest 2005;128(4):2984-2990.

45. Racca F, Appendini L, Berta G, Barberis L, Vittone F, Gregoretti C, et al. Helmet ventilation for acute respiratory failure and nasal skin breakdown in neuromuscular disorders. Anesth Analg 2009;109 (1):164-167.

46. Fabry B, Guttmann J, Eberhard L, Bauer T, Haberthür C, Wolff G. An analysis of desynchronization between the spontaneously breathing patient and ventilator during inspiratory pressure support. Chest 1995;107(5):1387-1394.

47. Fink JB. Device and equipment evaluations. Respir Care 2004;49 (10):1157-1164.

48. Thille AW, Rodriguez P, Cabello B, Lellouche F, Brochard L. Patient-ventilator asynchrony during assisted mechanical ventilation. Intensive Care Med 2006;32(10):1515-1522.

49. Petrof BJ, Legaré M, Goldberg P, Milic-Emili J, Gottfried SB. Continuous positive airway pressure reduces work of breathing and dyspnea during weaning from mechanical ventilation in severe chronic obstructive pulmonary disease. Am Rev Respir Dis 1990;141 (2):281-289.

50. Appendini L, Patessio A, Zanaboni S, Carone M, Gukov B, Donner CF, Rossi A. Physiologic effects of positive end-expiratory pressure and mask pressure support during exacerbations of chronic obstructive pulmonary disease. Am J Respir Crit Care Med 1994;149 (5): $1069-1076$

51. Younes M, Kun J, Webster K, Roberts D. Response of ventilator-dependent patients to delayed opening of exhalation valve. Am J Respir Crit Care Med 2002;166(1):21-30.

52. Javaheri S, Kazemi H. Metabolic alkalosis and hypoventilation in humans. Am Rev Respir Dis 1987;136(4):1011-1016.

53. Vaschetto R, Cammarota G, Colombo D, Longhini F, Grossi F, Giovanniello A. Effects of propofol on patient-ventilator synchrony and interaction during pressure support ventilation and neurally adjusted ventilatory assist. Crit Care Med 2014;42(1):74-82.

54. Bassuoni AS, Elgebaly AS, Eldabaa AA, Elhafz AA. Patient-ventilator asynchrony during daily interruption of sedation versus no sedation protocol. Anesth Essays Res 2012;6(2):151-156.

55. Strøm T, Martinussen T, Toft P. A protocol of no sedation for critically ill patients receiving mechanical ventilation: a randomised trial. Lancet 2010;375(9713):475-480.

56. de Wit M, Miller KB, Green DA, Ostman HE, Gennings C, Epstein SK. Ineffective triggering predicts increased duration of mechanical ventilation. Crit Care Med 2009;37(10):2740-2745.

57. Brochard L. Pressure support ventilation. In: Tobin MJ, editor. Principles and practice of mechanical ventilation. New York: McGraw-Hill; 1994:239-257.

58. Chiumello D, Polli F, Tallarini F, Chierichetti M, Motta G, Azzari S, et al. Effect of different cycling-off criteria and positive end-expiratory pressure during pressure support ventilation in patients with chronic obstructive pulmonary disease. Crit Care Med 2007;35 (11):2547-2552.

59. Yamada Y, Du HL. Analysis of the mechanisms of expiratory asynchrony in pressure support ventilation: a mathematical approach. J Appl Physiol 2000;88(6):2143-2150.

60. Murata S, Yokoyama K, Sakamoto Y, Yamashita K, Oto J, Imanaka $\mathrm{H}$, Nishimura M. Effects of inspiratory rise time on triggering workload during pressure-support ventilation: a lung model study. Respir Care 2010;55(7):878-884.
61. Calderini E, Confalonieri M, Puccio PG, Francavilla N, Stella L, Gregoretti C. Patient-ventilator asynchrony during noninvasive ventilation: the role of expiratory trigger. Intensive Care Med 1999;25 (7):662-667.

62. Gregoretti C, Foti G, Beltrame F, Giugiaro PM, Biolino P, Burbi L, et al. Pressure control ventilation and minitracheotomy in treating severe flail chest trauma. Intensive Care Med 1995;21(12):10541056.

63. Vignaux L, Vargas F, Roeseler J, Tassaux D, Thille AW, Kossowsky MP, et al. Patient-ventilator asynchrony during non-invasive ventilation for acute respiratory failure: a multicenter study. Intensive Care Med 2009;35(5):840-846.

64. Vitacca M, Bianchi L, Zanotti E, Vianello A, Barbano L, Porta R, Clini E. Assessment of physiologic variables and subjective comfort under different levels of pressure support ventilation. Chest 2004;126 (3):851-859.

65. Imanaka H, Nishimura M, Takeuchi M, Kimball WR, Yahagi N, Kumon K. Autotriggering caused by cardiogenic oscillation during flow-triggered mechanical ventilation. Crit Care Med 2000;28 (2):402-407.

66. Branson RD, Blakeman TC, Robinson B. Asynchrony and dyspnea. Respir Care 2013;58(6):973-989.

67. Tokioka H, Tanaka T, Ishizu T, Fukushima T, Iwaki T, Nakamura Y, Kosogabe Y. The effect of breath termination criterion on breathing patterns and the work of breathing during pressure support ventilation. Anesth Analg 2001;92(1):161-165.

68. de Haro C, López-Aguilar J, Magrans R, Montanya J, FernándezGonzalo S, Turon M, et al. Double cycling during mechanical ventilation: frequency, mechanisms, and physiologic implications. Crit Care Med 2018;46(9):1385-1392.

69. de Haro C, Ochagavia A, López-Aguilar J, Fernandez-Gonzalo S, Navarra-Ventura G, Magrans R, et al. Patient-ventilator asynchronies during mechanical ventilation: current knowledge and research priorities. Intensive Care Med Exp 2019; 7(Suppl 1):43.

70. Kallet RH, Corral W, Silverman HJ, Luce J. Implementation of a low tidal volume ventilation protocol for patients with acute lung injury or acute respiratory distress syndrome. Respir Care 2001;46 (10): 1024-1037.

71. Correger E, Murias G, Chacon E, Estruga A, Sales B, Lopez-Aguilar $\mathrm{J}$, et al. Interpretation of ventilator curves in patients with acute respiratory failure. Med Intensiva 2012;36(4):294-306.

72. Subirà $\mathrm{C}$, de Haro $\mathrm{C}$, Magrans $\mathrm{R}$, Fernández R, Blanch L. Minimizing asynchronies in mechanical ventilation: current and future trends. Respir Care 2018;63(4):464-478.

73. Kallet RH, Campbell AR, Dicker RA, Katz JA, Mackersie RC. Work of breathing during lung-protective ventilation in patients with acute lung injury and acute respiratory distress syndrome: a comparison between volume and pressure-regulated breathing modes. Respir Care 2005;50(12):1623-1631.

74. Murias G, de Haro C, Blanch L. Does this ventilated patient have asynchronies? Recognizing reverse triggering and entrainment at the bedside. Intensive Care Med 2016;42(6):1058-1061.

75. Akoumianaki E, Lyazidi A, Rey N, Matamis D, Perez-Martinez N, Giraud R, et al. Mechanical ventilation-induced reverse-triggered breaths: a frequently unrecognized form of neuromechanical coupling. Chest 2013;143(4):927-938.

76. Parsons PE, Wiener-Kronish JP, Berra L, Stapleton RD. General intensive care unit. In: Critical care secrets, 6th edition. Philadelphia: Elsevier; 2018:54.

77. Gilstrap D, MacIntyre N. Patient-ventilator interactions: implications for clinical management. Am J Respir Crit Care Med 2013;188 (9):1058-1068. 


\section{Patient-Ventilator AsynChronies}

78. Yang LY, Huang YC, Macintyre NR. Patient-ventilator synchrony during pressure-targeted versus flow-targeted small tidal volume assisted ventilation. J Crit Care 2007;22(3):252-257.

79. Shelledy DC, Peters JI. Patient stabilization: adjusting ventilatory support. In: Mechanical ventilation. Burlington, MA: Jones \& Bartlett; 2019:373.

80. Younes M. Interactions between patients and ventilators. In: Roussos C, editor. Thorax, 2nd ed. New York: Marcel Dekker; 1995:23672420.

81. Murias G, Lucangelo U, Blanch L. Patient-ventilator asynchrony. Curr Opin Crit Care 2016;22(1):53-59.

82. Colombo D, Cammarota G, Bergamaschi V, De Lucia M, Corte FD, Navalesi P. Physiologic response to varying levels of pressure support and neurally adjusted ventilatory assist in patients with acute respiratory failure. Intensive Care Med 2008;34(11):2010-2018.

83. Gutierrez G, Ballarino GJ, Turkan H, Abril J, De La Cruz L, Edsall $\mathrm{C}$, et al. Automatic detection of patient-ventilator asynchrony by spectral analysis of airway flow. Crit Care 2011;15(4):R167.

84. Chao DC, Scheinhorn DJ, Stearn-Hassenpflug M. Patient-ventilator trigger asynchrony in prolonged mechanical ventilation. Chest 1997;112(6): 1592-1599.

85. Blanch L, Villagra A, Sales B, Montanya J, Lucangelo U, Luján M, et al. Asynchronies during mechanical ventilation are associated with mortality. Intensive Care Med 2015;41(4):633-641.

86. Yang L, Luo J, Bourdon J, Lin MC, Gottfried SB, Petrof B. Controlled mechanical ventilation leads to remodeling of the rat diaphragm. Am J Respir Crit Care Med 2002;166(8):1135-1140.

87. Radell PJ, Remahl S, Nichols DG, Eriksson LI. Effects of prolonged mechanical ventilation and inactivity on piglet diaphragm function. Intensive Care Med 2002;28(3):358-364.

88. Levine S, Biswas C, Dierov J, Barsotti R, Shrager JB, Nguyen T, et al. Increased proteolysis, myosin depletion, and atrophic AKTFOXO signaling in human diaphragm disuse. Am J Respir Crit Care Med 2011;183(4):483-490.

89. Levine S, Nguyen T, Taylor N, Friscia ME, Budak MT, Rothenberg $\mathrm{P}$, et al. Rapid disuse atrophy of diaphragm fibers in mechanically ventilated humans. N Engl J Med 2008;358(13):1327-1335.

90. Hermans G, Agten A, Testelmans D, Decramer M, Gayan-Ramirez G. Increased duration of mechanical ventilation is associated with decreased diaphragmatic force: a prospective observational study. Crit Care 2010;14(4):R127.

91. Hussain SN, Mofarrahi M, Sigala I, Kim HC, Vassilakopoulos T, Maltais F, et al. Mechanical ventilation-induced diaphragm disuse in humans triggers autophagy. Am J Respir Crit Care Med 2010;182 (11):1377-1386.

92. Kondili E, Prinianakis G, Georgopoulos D. Patient-ventilator interaction. Br J Anaesth 2003;91(1):106-119.

93. Hunter KD, Faulkner JA. Pliometric contraction-induced injury of mouse skeletal muscle: effect of initial length. J Appl Physiol (1985) 1997;82(1):278-283.

94. Devor ST, Faulkner JA. Regeneration of new fibers in muscles of old rats reduces contraction-induced injury. J Appl Physiol (1985) 1999;87(2):750-756.

95. Hirose L, Nosaka K, Newton M, Laveder A, Kano M, Peake J, Suzuki K. Changes in inflammatory mediators following eccentric exercise of the elbow flexors. Exerc Immunol Rev 2004; 10:75-90.

96. Gosselin LE, Burton H. Impact of initial muscle length on force deficit following lengthening contractions in mammalian skeletal muscle. Muscle Nerve 2002;25(6):822-827.

97. Bosma K, Ferreyra G, Ambrogio C, Pasero D, Mirabella L, Braghiroli A, et al. Patient-ventilator interaction and sleep in mechanically ventilated patients: pressure support versus proportional assist ventilation. Crit Care Med 2007;35(4):1048-1054.
98. Parthasarathy S, Tobin MJ. Effect of ventilator mode on sleep quality in critically ill patients. Am J Respir Crit Care Med 2002;166 (11): 1423-1429.

99. Alexopoulou C, Kondili E, Plataki M, Georgopoulos D. Patient-ventilator synchrony and sleep quality with proportional assist and pressure support ventilation. Intensive Care Med 2013;39(6):1040-1047.

100. Delisle S, Ouellet P, Bellemare P, Tétrault JP, Arsenault P. Sleep quality in mechanically ventilated patients: comparison between NAVA and PSV modes. Ann Intensive Care 2011;1(1):42.

101. Schmidt M, Demoule A, Polito A, Porchet R, Aboab J, Siami S, et al. Dyspnea in mechanically ventilated critically ill patients. Crit Care Med 2011;39(9):2059-2065.

102. Herridge MS, Tansey CM, Matté A, Tomlinson G, Diaz-Granados N, Cooper A, et al. Functional disability 5 years after acute respiratory distress syndrome. N Engl J Med 2011;364(14):1293-1304.

103. Trompeo AC, Vidi Y, Locane MD, Braghiroli A, Mascia L, Bosma K, Ranieri VM. Sleep disturbances in the critically ill patients: role of delirium and sedative agents. Minerva Anestesiol 2011;77(6):604612.

104. Mistraletti G, Pelosi P, Mantovani ES, Berardino M, Gregoretti C. Delirium: clinical approach and prevention. Best Pract Res Clin Anaesthesiol 2012;26(3):311-326.

105. Dres M, Rittayamai N, Brochard L. Monitoring patient-ventilator asynchrony. Curr Opin Crit Care 2016;22(3):246-253.

106. Georgopoulos D, Prinianakis G, Kondili E. Bedside waveforms interpretation as a tool to identify patient-ventilator asynchronies. Intensive Care Med 2006;32(1):34-47.

107. Fernández-Pérez ER, Hubmayr RD. Interpretation of airway pressure waveforms. Intensive Care Med 2006;32(5):658-659.

108. Vignaux L, Grazioli S, Piquilloud L, Bochaton N, Karam O, Jaecklin $\mathrm{T}$, et al. Optimizing patient-ventilator synchrony during invasive ventilator assist in children and infants remains a difficult task. Pediatr Crit Care Med 2013;14(7):316-325.

109. Georgopoulos D. Ineffective efforts during mechanical ventilation: the brain wants, the machine declines. Intensive Care Med 2012;38 (5):738-740.

110. Colombo D, Cammarota G, Alemani M, Carenzo L, Barra FL, Vaschetto R, et al. Efficacy of ventilator waveforms observation in detecting patient-ventilator asynchrony. Crit Care Med 2011;39 (11):2452-2457.

111. Chacón E, Estruga A, Murias G, Sales B, Montanya J, Lucangelo U, et al. Nurses' detection of ineffective inspiratory efforts during mechanical ventilation. Am J Crit Care 2012;21(4):e89-.

112. Chen CW, Lin WC, Hsu CH. Pseudo-double-triggering. Intensive Care Med 2007;33(4):742-743.

113. Brochard L. Measurement of esophageal pressure at bedside: pros and cons. Curr Opin Crit Care 2014;20(1):39-46.

114. Gogineni VK, Brimeyer R, Modrykamien A. Patterns of patient-ventilator asynchrony as predictors of prolonged mechanical ventilation. Anaesth Intensive Care 2012;40(6):964-970.

115. Doorduin J, van Hees HW, van der Hoeven JG, Heunks LM Monitoring of the respiratory muscles in the critically ill. Am J Respir Crit Care Med 2013;187(1):20-27.

116. Parthasarathy S, Jubran A, Tobin MJ. Assessment of neural inspiratory time in ventilator-supported patients. Am J Respir Crit Care Med 2000;162(2 Pt 1):546-552.

117. Goligher EC, Laghi F, Detsky ME, Farias P, Murray A, Brace D, et al. Measuring diaphragm thickness with ultrasound in mechanically ventilated patients: feasibility, reproducibility and validity. Intensive Care Med 2015;41(4):642-649.

118. Matamis D, Soilemezi E, Tsagourias M, Akoumianaki E, Dimassi S, Boroli F, et al. Sonographic evaluation of the diaphragm in critically ill patients: technique and clinical applications. Intensive Care Med 2013;39(5):801-810. 


\section{Patient-Ventilator AsynChronies}

119. Chen CW, Lin WC, Hsu CH, Cheng KS, Lo CS. Detecting ineffective triggering in the expiratory phase in mechanically ventilated patients based on airway flow and pressure deflection: feasibility of using a computer algorithm. Crit Care Med 2008;36(2):455-461.

120. Mulqueeny Q, Redmond SJ, Tassaux D, Vignaux L, Jolliet P, Ceriana $\mathrm{P}$, et al. Automated detection of asynchrony in patient-ventilator interaction. Conf Proc IEEE Eng Med Biol Soc 2009;2009:5324-5327.

121. Younes M, Brochard L, Grasso S, Kun J, Mancebo J, Ranieri M, et al. A method for monitoring and improving patient: ventilator interaction. Intensive Care Med 2007;33(8):1337-1346.

122. Blanch L, Sales B, Montanya J, Lucangelo U, Garcia-Esquirol O, Villagra A, et al. Validation of the Better Care system to detect ineffective efforts during expiration in mechanically ventilated patients: a pilot study. Intensive Care Med 2012;38(5):772-780.

123. Cuvelier A, Achour L, Rabarimanantsoa H, Letellier C, Muir JF, Fauroux B. A noninvasive method to identify ineffective triggering in patients with noninvasive pressure support ventilation. Respiration 2010;80(3):198-206.

124. Leung RS, Bradley TD. Sleep apnea and cardiovascular disease. Am J Respir Crit Care Med 2001;164(12):2147-2165.

125. Carlucci A, Pisani L, Ceriana P, Malovini A, Nava S. Patient-ventilator asynchronies: may the respiratory mechanics play a role? Crit Care 2013;17(2):R54

126. Gottfried SB. The role of PEEP or CPAP in the mechanically ventilated COPD patient. In: Marini JJ, Roussos C, editor. Ventilatory failure. New York: Marcel Dekker; 1991:2471-2500.

127. Mancebo J, Albaladejo P, Touchard D, Bak E, Subirana M, Lemaire F, et al. Airway occlusion pressure to titrate positive end-expiratory pressure in patients with dynamic hyperinflation. Anesthesiology 2000;93(1):81-90.

128. de Wit M, Pedram S, Best AM, Epstein SK. Observational study of patient-ventilator asynchrony and relationship to sedation level. J Crit Care 2009;24(1):74-80.

129. Conti G, Ranieri VM, Costa R, Garratt C, Wighton A, Spinazzola G, et al. Effects of dexmedetomidine and propofol on patient-ventilator interaction in difficult-to-wean, mechanically ventilated patients: a prospective, open-label, randomised, multicentre study. Crit Care 2016;20(1):206.

130. Costa R, Navalesi P, Cammarota G, Longhini F, Spinazzola G, Cipriani F, et al. Remifentanil effects on respiratory drive and timing during pressure support ventilation and neurally adjusted ventilatory assist. Respir Physiol Neurobiol 2017;244:10-16.

131. Piquilloud L, Vignaux L, Bialais E, Roeseler J, Sottiaux T, Laterre $\mathrm{PF}$, et al. Neurally adjusted ventilatory assist improves patient-ventilator interaction. Intensive Care Med 2011;37(2):263-271.

132. de la Oliva P, Schüffelmann C, Gómez-Zamora A, Villar J, Kacmarek R. Asynchrony, neural drive, ventilatory variability and COMFORT: NAVA versus pressure support in pediatric patients. A non-randomized cross-over trial. Intensive Care Med 2012;38 (5):838-846.

133. Costa R, Spinazzola G, Cipriani F, Ferrone G, Festa O, Arcangeli A, et al. A physiologic comparison of proportional assist ventilation with load-adjustable gain factors (PAV+) versus pressure support ventilation (PSV). Intensive Care Med 2011;37(9):1494-1500.

134. Kacmarek RM. Proportional assist ventilation and neurally adjusted ventilatory assist. Respir Care 2011;56(2):140-148.

135. Schmidt M, Kindler F, Cecchini J, Poitou T, Morawiec E, Persichini $\mathrm{R}$, et al. Neurally adjusted ventilatory assist and proportional assist ventilation both improve patient-ventilator interaction. Crit Care 2015;25:19-56.

136. Yonis H, Crognier L, Conil JM, Serres I, Rouget A, Virtos M, et al. Patient-ventilator synchrony in neurally adjusted ventilatory assist (NAVA) and pressure support ventilation (PSV): a prospective observational study. BMC Anesthesiol 2015;15:117.

137. Huhle R, Pelosi P, de Abreu MG. Variable ventilation from bench to bedside. Crit Care 2016;20:62.

138. Spieth PM, Carvalho AR, Pelosi P, Hoehn C, Meissner C, Kasper M, et al. Variable tidal volumes improve lung protective ventilation strategies in experimental lung injury. Am J Respir Crit Care Med 2009;179(8):684-693.

139. Spieth PM, Güldner A, Huhle R, Beda A, Bluth T, Schreiter D, et al. Short-term effects of noisy pressure support ventilation in patients with acute hypoxemic respiratory failure. Crit Care 2013;17(5): R261. 